\title{
REFLEXIONES AGERGA DE LA ESTRUCTURA DEL RAZONAMIENTO JUDICIAL
}

\author{
Carlos I. Massini
}

Profesor de Filosofía del Derecho

Facultad de Derecho Univ. de Mendoza

(Argentina)

$\begin{array}{lllllll}S & \mathrm{U} & \mathbf{M} & \mathbf{A} & \mathrm{R} & \mathbf{I} & \mathrm{O}\end{array}$

Introducción. I. La concepción moderna. II. La codificación y la exégesis. 1II. Crítica del dogmatismo silogístico. IV. La reacción realista. v. La contingencia de lo jurídico. vi. La practicidad del razonamiento judicial. vir. Carácter valioso del juicio. virr. El juicio prudencial.

El tema del modo propio del pensar judicial o de la forma especifica y particular como piensan los jueces, es de una vastedad y com. plejidad que excede con creces los límites de un breve ensayo. Por esta razón, sólo vamos a realizar aquí a gunas reflexiones someras y esquemáticas, esbozo de un tema acerca del que tenemos en elaboración un trabajo de más largo aliento, de concreción final ya dema. siado postergada. Estas reflexiones se moverán en el plano estrictamente filosófico, sin hacer mención al derecho positivo, vigente o histórico. Esto puede descorazonar a quienes no se encuentran familiarizados con las categorías filosóficas y sí con las propias de la legalidad positiva; no obstante, creemos que es imprescindible distinguir adecuadamente los planos del saber y no incurrir en confusiones o traspolaciones que terminan casi siempre confundiendo a la inteligencia.

El problema al que pretendemos dar comienzo de respuesta pue de ser planteado en los siguientes términos: ¿mediante qué procedimiento intelectual llega el juez a decidir la solución de un caso concreto?; ¿de qué medios o procedimientos lógicos se vale para elaborar su sentencia?; en definitiva: ¿cuál es el método del razonamiento 
jurídico, en especial del que conduce a la decisión de un magistra. do? ¿cuál es su estructura nocional?

Un aforismo clásico, de una verdad evidente e incuestionable, afirma que el método de conocimiento depende de la naturaleza del objeto; el camino a seguir para descubrir la esencia de una cosa, depende de la naturaleza de esa misma cosa y no de consideraciones de otra índole ${ }^{1}$. No se puede estudiar la vida de las abejas con los procedimientos de la geometría, ni la degeneración de las células con los instrumentos nocionales de la historia. Dice a este respecto Aristóteles, que "es propio del hombre instruido buscar la exactitud en cada género de conocimiento en la medida en que lo admite la naturaleza de la materia; evidentemente, tan absurdo sería aprobar a un matemático que empleara la persuasión, como reclamar demostraciones exactas a un retórico"'2.

En razón de lo expuesto, es bien claro que según cuál sea la concepción del derecho de que partamos, distinto será el método que propondremos para su elaboración y conocimiento. El razonamiento jurídico será, por esto, necesariamente desigual conforme aceptemos un concepto realista, subjetivista, normativista, etc., de lo jurídico.

$$
\text { I. L A C O }
$$

El pensamiento moderno, del que aún hoy somos herederos, partió de una concepción normativista del derecho. Este normativismo se explica en razón de las notas o caracteres del pensamiento jurídico de la modernidad.

1) El primero de estos caracteres es el racionalismo.

En el ámbito de lo jurídico, racionalismo significa, en primer lugar y como bien afirma D'Entreves, la desvinculación de la razón de la experiencia y de la sabiduría teológica ${ }^{3}$. Esta razón, cortados los lazos con lo real y lo sobrenatural, que le daban fundamentos objetivos, pretendió construir la realidad sobre la base del modelo matemático. El campo de las matemáticas satisfacía plenamente las exigencias de la razón pura: era totalmente ajeno a lo real empírico, cambiante y mudable, y en él se llegaba a resultados ciertos y

${ }^{1}$ Cfr. R. Jolivet, Tratado de Filosofia (Lógica). Carlos Lohlé. Buenos Aires. 1976.

Aristóteles, Etica a Nicómano, 1, 3.

${ }^{3}$ A. P. D'Entrèves, Derecho Natural. Aguilar. Madrid. 1972, 61 ss. 
necesarios. En este campo, la razón pura se encontraba a sus anchas ${ }^{4}$.

Dado el éxito de la razón en el ámbito matemático, la solución más coherente al problema del método parecía ser aplicar el de las matemáticas a todas las ciencias, en especial a las ciencias prácticas, cuyo objeto es el obrar humano. Espinosa, refiriéndose a la ética, no deja dudas acerca de este propósito: "consideraré las acciones y los apetitos humanos -escribe- como si se tratase de líneas, de superficies y de cuerpos sólidos"5.

En lo que al derecho respecta, esto significa lisa y llanamente la construcción de toda la realidad jurídica al modo de un teorema: partiendo de un postulado y deduciendo sucesivamente una serie de conclusiones, que nos darán racionalmente la totalidad del ordenamiento jurídico. Hasta la más concreta y detallada de las reglas de derecho, será deducida del principio tomado apriorísticamente como postulado.

Fruto de este modo de razonar, fueron los enormes tratados de Derecho Natural, elaborados en los siglos xvi y xviI y en los que se pretendió, absurdamente, contener todo el derecho racional, de una vez para siempre y con validez universal. "Nosotros constatamos -escribe Michel Villey- que las grandes obras de la época moderna han cultivado efectivamente este método deductivo. Si se trata de la elaboración del cuerpo de reglas jurídicas, es la edad de los sistemas tales como el de Grocio, de Pufendorf, de Domat (...). Y si se trata de la aplicación del derecho en la etapa judicial, la doctrina moderna nos invita a extraer la sentencia deductivamente de las reglas de derecho, ya se encuentren codificadas en las grandes obras de doctrina, ya puestas en los textos de las leyes por la voluntad más o menos arbitraria del legislador"6. El método racional deductivo se convierte en método único del derecho, ya sea para la creación de las reglas, ya para su aplicación a un caso concreto. Todo el proceso es obra de la razón; la experiencia, que nos da lo singular y contin-

${ }^{4}$ En verdad -escribia Grocio- yo declaro explícitamente que, como las matemáticas consideran las figuras haciendo abstracción de los cuerpos, así yo, al tratar del derecho he separado mi pensamiento de cualquier hecho particular. (Grocio, De iure belli ac pacis, Prolegómenos. No 58, cit. por D'Entrèves, 67) .

${ }^{5}$ Espinoza, Etica. Aguilar. Buenos Aires. 1973, 161.

${ }^{6} \mathrm{M}$. Villey, Questions de logique juridique dans l'histoire de la philosophie du droit, en Logique et Analyse (Paris-Louvain) № 37. (1967) 6. 
gente, lo que escapa a la certeza y necesidad de la matemática, es dejada de lado con un gesto de desprecio.

Consecuencia del racionalismo son el sistematismo y el abandono de la filosofía práctica.

2) EI sistematismo, el segundo de los caracteres, deriva de la apli. cación del método racional-deductivo hasta sus últimas consecuencias, lo que conduce a la formación de sistemas cerrados y completos de conocimiento, en los que cada afirmación puede ser reconducida al primer principio a partir del que toda deducción comienza. Afirma a este respecto Theodor Wiehweg que la sistematización "se obtiene conforme al método axiomático, que consiste en ordenar de acuerdo con su dependencia lógica, los conceptos y afirmaciones en un terreno cualquiera $(.$.$) ; todas las proposiciones de ese saber$ pueden ser derivadas por medio de un simple procedimiento lógico, es decir, obteniendo conclusiones correctas a través de una cadena de deducciones"7. El derecho - desde esta perspectiva- se nos presenta como una estructura cerrada, sin ningún contacto con la realidad vital exterior y totalmente coherente en el orden interno. El sistema jurídico podía ser conceptualizado en forma totalmente independiente de lo real, social e histórico; el sistema se bastaba a sí mismo, no necesitaba ayuda alguna del exterior, descansaba tranquilo en la armonía e interrelación de sus partes.

3) De lo expuesto, y éste es el tercero de los caracteres, resulta necesariamente la repulsa del pensamiento práctico y de todo lo que se refiere a los fines del obrar. Este hecho, que ha sido magnífica. mente puesto de relieve por Wilhem Hennis en su libro "Política y filosofía práctica"9, consiste en la exclusión deliberada, del sistema del pensamiento, de todo lo referente al obrar humano y a sus

'T. Viehweg, Tópica y jurisprudencia. Taurus. Madrid. 1964, 113. Un claro exponente del sistematismo del pensamiento moderno, es el libro de J. G. Fichte, Sobre el concepto de la doctrina de la ciencia. unam. México. 1963, sobre todo 13, 16, 20, 20, 32 y 45 .

${ }^{8} \mathrm{Cfr}$. G. Graneris, La filosofia del diritto nella sua storia $e$ nei suoi problemi. Desclée. Roma. 1961, 213. (Hay traducción chilena).

"W Hennis, Politica y filosofía práctica. Sur. Buenos Aires. 1973. 48 ss. Véase a este respecto: E. Zuleta Puceiro, Consideraciones en torno a la obra politica y filosofia práctica de W. Hennis, en Ethos No 1 . (Instituto de Filosofía Práctica). Buenos Aires. 1973, 325, 311, y también F. Inciarte Arminán, El reto del positivismo lógico. Rialp. Madrid. 1974, caps. vi $\mathrm{y}$ VII. 
fines propios; de todo lo que se vincula con la historia, con el cambio de situaciones, con la contingencia y singularidad de la vida personal y social del hombre. Ello en razón de que estas realidades no entran en los esquemas lógico deductivos propios de las ciencias exactas. Es sabido que para los modernos no existe otro tipo de ciencia que aquella que pueda expresarse a través de leyes formulables matemáticamente; sólo éstas responden a su ideal metódico de certeza absoluta y a su confesada ambición de saber para dominar técnicamente al mundo, expresada en la tan citada frase de Bacon: "el saber es poder".

Dentro de esta concepción de la ciencia, no tienen evidentemente lugar los fines del obrar humano - que no son medibles matemáticamente- y que constituyen el fundamento de los saberes prácticos, los que versan sobre la moral, la política y el derecho. Para el concepto moderno de ciencia, el derecho, la política, la moral, no constituían saberes dignos de ser tenidos en cuenta. Todos ellos se ordenan a ciertos y determinados fines y los fines habian sido excluidos, por principio, del campo de lo cognoscible. Los intentos que se hagan en la época moderna de tratar alguna de esas realidades, no lo harán al modo práctico, como saberes destinados a dirigir el obrar del hombre, sino al modo teórico o especulativo y tomando por modelo metodológico el de las ciencias exactas 10.

4) Para un pensamiento puramente racionalista, sistemático y que ha excluido de su ámbito los fines, lo contingente, lo existencial y mudable, es claro que sólo las normas -ordenaciones de la razónpueden ser objeto de conocimiento. El normativismo, la última de las notas, es perfectamente coherente con los supuestos del pensamiento moderno: en efecto, la norma es la única dentro de las realidades jurídicas que puede ser ordenada en sistema la única con que puede trabajarse racionalmente, abstracción hecha de la realidad concreta; la única que puede pensarse al modo teórico o especulativo, con prescindencia metodológica de los fines humanos. Con las normas consideradas abstractamente, pensadas en sí mismas y desvinculadas de toda realidad humana social, se puede realizar cualquier tipo de elucubración ideal; se pueden construir sistemas doctrinariamente perfectos o esquemas lógicamente coherentes y acabados.

No ocurne lo mismo con las demás realidades jurídicas: ni el con-

${ }^{10}$ Cfr. M. Villey, Philosophie du droit. Dalloz. Paris. 1975, 196 ss. 
creto obrar social justo, ni los fallos de los tribunales, ni los deberes o facultades jurídicas, pueden ser concebidas sin vinculación directa con lo real concreto. Sólo las normas son susceptibles de un tratamiento puramente racional, permiten la construcción de sistemas y pueden ser concebidas teóricamente, abstracción hecha de las finalidades del hombre11.

\section{L A C O D I F I C A C I O $\mathrm{N} \quad \mathrm{Y} \quad$ L A $\quad$ E X E G E S I S}

Los artífices del pensamiento moderno lograron concretar estas ideas: el derecho concebido como un sistema de normas, elaboradas por la sola razón de una vez y para siempre, tomó forma concreta en los códigos elaborados en el crepúsculo de la edad moderna. Y si el derecho se encontraba soamente en los códigos, era necesario que su aplicación al caso concreto se realizara mediante un silogismo estricto, tal como se aplica una ley física a un fenómeno cualquiera. La Escuela de la Exégesis fue la concreción más acabada de este modo de pensamiento, sin que los pandectistas alemanes, con su conceptualismo al estilo de Windscheid, escaparan a la tentación de concebir el derecho en el mundo de los conceptos abstractos, separados de la realidad por un abismo infranqueable ${ }^{12}$.

Según el eminente jurista español Manuel García Pelayo13, las principales tesis de estas escuelas, que podemos denominar conceptualistas o dogmáticas, pueden reducirse a las siguientes:

1) El jurista ha de atenerse al derecho positivamente dado, a las leyes sancionadas por el Estado y contenidas en los códigos. Este positivismo jurídico, no debe ser confundido con el positivismo filosófico que, con otros fundamentos, vendrá con posterioridad a sostener una postura similar. Para el positivismo racionalista, el derecho san-

${ }^{11} \mathrm{El}$ racionalismo no es, en puridad de verdad, la única fuente del normativismo moderno, sino que también lo es el voluntarismo, presente desde Suárez a Rousseau. Han expuesto este tema en forma precisa, entre otros, A. Vincent, La notion moderne du droit naturel et le volontarisme (de Suárez a Rousseau) en APD No 8 (1963). 237 ss. y M. Villey, Essor et décadence du volontarisme juridique, en APD No 2 (1958) 87 ss. H. Rommen, Derecho Nattural, Jus. México, 1950, 141 ss.

${ }^{13}$ Cfr. A. Hernández Gil, Metodologia de la ciencia del Derecho, sF. Madrid, I (1971). 78 ss. y 127 ss.

${ }^{18} \mathrm{M}$. Garcla Pelayo, Derecho Constitucional Comparado. Rer. de Occidente. Madrid. 1964, 58 . 
cionado en los códigos no era sino la positivación de los principios universales y eternos del derecho racional. "En esa ideologia -escribe Francesco Olgiati- la antítesis entre el derecho natural y el carácte: estatal del derecho venía superada por la razón misma, fuente de los principios inmortales del estado moderno y de las modernas legislaciones"14. Y en este mismo sentido, escribe Hernández Gil, que "es la fe tn el ho.sbre portador de la razón y la fe en el poder omnimodo del legislador, en cuanto le es dado transformar la razón en ley escrita, la verdadera causa dese minante de scs Códigos"15.

2) La ciencia juridica tiene carcicter reproductivo o teórico; no discute ni valora, sino que para ella el derecho positivo es dogma. Y como tal dogma es objeto de estudio al modo especulativo, realizado con el fin de extraer las virtualidades contenidas en los textos legales, sin otro fin ulterior que conocer su perfección por su perfec. ción misma16.

3) Frente al hecho del derecho positivo, el jurista actúa con un método abstractivo generalizador, con el fin de formular unos conceptos comunes y principios generales teóricos, con validez para todo el conjunto.

4) Los conceptos, principios y normas se conexionan entre si hasta formar un sistema, es decir, una ordenación sin contradicciones y en la que es posible subsumir cualquier caso.

5) La labor del jurista y sobre todo del juez, se reduce a pura lógica deductiva, mediante la cual se explicitan, para el caso singular, los conceptos, normas y principios; todo ello excluyendo cualquier consideración o referencia de índole histórica, sociológica, va. lorativa, o de cualquier otra índole.

Todos estos caracteres pueden reducirse a uno y principal, a partir del cual se comprenden: el concebir el derecho al modo teórico o especulativo. A los efectos de clarificar el tema, recordemos la división del saber, efectuada ya por Aristóteles, entre un modo teórico - especulativo y uno práctico o normativo de conocer ${ }^{17}$. Para el pen-

${ }_{14} \mathrm{~F}$. Olgiati, Il concetto di giuridicità nella scienza moderna del diritto. Vita e Pensiero. Milano. 1943. 11. (Hay traducción española).

${ }^{18} \mathrm{G}$. Hernández, op. cit. 79.

${ }^{10} \mathrm{Cfr}$. L. Recasens Siches, Nueva filosofia de la interpretacion del derecho. Porrúa. México. 1973. 154s.

${ }^{17}$ Cfr. Aristóteles, Etica a Nicomaco, II, 2; vI, 5; x, 8 y 9. 
samiento clásico que arranca en este filósofo, existen dos modos o formas de usar la razón: por uno, el teórico, la inteligencia conoce las estructuras de las cosas con el sólo propósito de conocerlas; su fin es la contemplación o teoría de lo real. El objeto propio de este modo de saber es la realidad dada, aquélla que existe con independencia de la acción humana; lo que llamamos comúnmente el orden de la naturaleza.

Por el modo práctico de emplear el intelecto, se busca no ya co. nocer por el solo conocer, por el placer de la posesión de la verdad, sino para dirigir el obrar humano, sea éste individual o social. Se trata de un saber normativo, que elabora pautas de acción y que tiene por objeto las realidades operables, o sea, aquéllas que el hombre realiza para su propia perfección o realización entitativa.

En el conocimiento teórico, el entendimiento refleja la realidad tal como es, busca su estructura intrínseca, sin importarle para nada una ulterior acción del hombre. Su objeto es fijo e inmutable y totalmente extraño a cualquier tipo de valoración ética. Su método es fundamentalmente analítico y el resultado de la investigación teórica es una verdad abstracta, general y universal.

El tipo ideal de este conocimiento especulativo es el de las mateInáticas: aqui se conoce sólo por conocer, su objeto se impone al hombre y se concluye, mediante procedimientos de lógica formal, en verdades puramente abstractas. Las valoraciones, por supuesto, están totalmente ausentes de este ámbito18.

El pensamiento jurídico moderno, obsesionado por el modelo matemático y -después de Kant- por el de la física, trató a las realidades práctico-jurídicas al modo teórico o especulativo.

No se trata de que se sostuviera expresamente que el derecho constituía un objeto especulable, sino de que se lo estudiaba como si lo fuera. El trabajo intelectual del jurista no diferia en nada, para esta concepción, del que realizaban el matemático o el físico; su método de conocimiento era igual; el modo y estructura del razonamiento, idénticos. Tal como ocurre en el campo de lo teórico, se partía en

${ }^{18}$ Para la distinción entre lo teórico y lo práctico, hemos seguido sobre todo a J. Maritain, Los grados del saber. Glub de Lectores. Buenos Aires. 1968, 725 ss. A. Rossi, Conocimiento especulativo y conacimiento práctico, en Actas del Primer Congreso Nacional de Filosofía. Tomo Ir. unc. Mendoza. 1950. 1195ss. L. E. Palacios, Filosofía del Saber. Gredos. Madrid. 1962, 157 ss; del mismo autor, La prudencia política. IEP. Madrid. 1945. 
ciencia juridica de un dato, de algo "dado", que cumplía la función del postulado matemático o de la hipótesis física. Este "dado" lo constituían los principios del derecho racional para el constituyente, las normas constitucionales para el legislador y las leyes para el magistrado. "Los códigos -escribía Laurent- no dejan nada al arbitrio del intérprete; éste no tiene por misión hacer el derecho; el derecho está hecho"19,

A partir de ese elemento dado, la sentencia se construía deductivamente, a través de un silogismo en donde la norma cumplía la función de premisa mayor, la situación concreta la de premisa menor y la norma singular y circunstanciada, la de conclusión o premisa menor. Se pretendió, por la escuela de la exégesis y en general por todos los conceptualistas, aplicar la norma al caso de modo análogo al que se utiliza para subsumir en una ley física un fenómeno de experiencia. Del mismo modo que partiendo del principio de que el calor dilata los metales y constatado que el hierro es un metal, se concluye necesariamente que el calor dilata el hierro, se sostuvo que, dada una norma positiva y un caso subsumible en dicha norma, debía concluirse también, necesaria y uniformemente, la decisión sin. gular de la situación jurídica planteada. Así se justifica lo afirmado por Liard, que "los artículos del código son teoremas cuyo enlace entre sí hay que demostrar y deducir sus consecuencias, hasta el punto que el verdadero jurista es un geómetra y la educación puramente juridica es puramente geométrica" 20 .

$$
\begin{aligned}
& \text { III. CRITICA DEL D O G M A T I S M O } \\
& \text { SI L O G I S T I G O }
\end{aligned}
$$

Esta doctrina es radicalmente errónea y lo es por varios motivos:

1) Es falsa porque supone, necesariamente, que existe un ordenamiento legal suficiente y completo. Para cualquier situación concreta, individual o colectiva, habría siempre una norma racionalmente cierta en el derecho positivo, que funcionaría como la premisa mayor universal del silogismo demostrativo. Pero resulta que la norma jurídica no tiene el carácter de ley universal que se pretende, como el cit. 82

${ }^{10}$ Laurent, Cours élémentaire de droit civil, cit. por Hernández Gil ${ }^{20}$ Liard, L'enseignement supérieur en France de 1879 a 1893, cit. por
L. Recasens Siches cit. 155 . 
de la premisa mayor del silogismo; la ley jurídica es una norma dictada por un legislador histórico con el fin de dar solución a un problema social determinado. Frente a una situación conflictiva, que dificulta o hace imposible la consecución del bien común, el gobernante establece aquella norma que servirá como directriz para la solución de esa situación problemática. No se trata de una ley universal, como la de que "todos los hombres son mortales" o que "el calor dilata los metales", sino de la solución dada en un lugar y un tiempo determinados, para superar un problema circunstanciado e irrepetible.

Además, el sistema legislativo no es completo, pues existen lagunas legales, ya sea por imprevisión del legislador o por el cambio ocurrido en las relaciones reguladas, estas últimas llamadas por Philiph Heck, lagunas sobrevinientes 21 .

Por último, existe frecuentemente la concurrencia de varias normas legales de sentido total o parcialmente contradictorio, que se re. fieren a uno o varios aspectos de una misma realidad, con un sentido opuesto o simplemente disímil.

Ante esta situación, la primera tarea del juez es la de buscar la norma atinente al caso planteado, búsqueda en la cual necesariamente debe obrar con un criterio valorativo; la determinación de cuál o cuáles son las reglas jurídicas aplicables, es ya un juicio de valor, pues significa elegir una entre muchas como la más adecuada para la solución de un caso singular. Significa un acto de elección en materia de obrar humano social, acto que no puede dejar de ser intrínsecamente valioso, lleno de contenido ético. No se da aquí esa ley universal bajo la que necesariamente ha de subsumirse el caso, sino una norma circunstanciada e histórica, que debe ser determinada mediante un juicio de valor, juicio que escapa -evidentementea los cánones estrictos de la lógica formal22.

2) La situación de hecho que debe regularse, también ha de ser

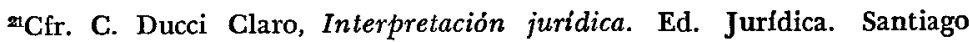
de Chile. 1977, 57.

${ }^{2} \mathrm{~A}$ este respecto véase $\mathrm{K}$. Engisch, Introducción al pensamiento juridico. Guadarrama. Madrid. 1967, 87 ss. M. Villey, Modes classiques d'interprétation du droit, en APD No 17 (1972) 85; J. M. Rodríguez Paniagua, Ley y derecho - Interpretación $e$ integración de la ley. Tecnos. Madrid, 1976, 100; E. García Maynes, Lógica del raciocinio juridico. FCE. México. 1964, 15 ss y 131 ss. y también Ducci Claro, op. cit. 60. 
objeto de una valoración por parte del magistrado; no se trata de algo cognoscible en forma directa, cierta e inmediata, sino de una realidad compleja que llega a conocimiento del magistrado a través de la prueba y que es valorada por éste. En algunos casos en forma evidente, pero en todos en mayor o en menor grado, el juez debe valorar, estimar los hechos; debe verificar su alcance, tratar de descubrir su sentido, emitir un juicio acerca del valor de los medios de prueba y de las pretensiones de las partes. Los hechos jurídicos no tienen el carácter axiológicamente neutro que pueden tener aquéllos que estudia la física; por el contrario, son hechos humanos libres realizados en la convivencia social, que en virtud de aquel carácter, son esencialmente valiosos o disvaliosos. En este sentido, ha escrito Miguel Reale que "el dato de la experiencia jurídica es siempre un contenido valioso, algo que implica un significado axiológico, que no puede ser tratado como un hecho natural ni explicado exclusivamente según nexos causales de coexistencia y sucesión"'23. El conocer este dato en el juicio, el juez - consciente o inconscientemente- lo valora, conforme a un criterio acerca de lo justo y de
lo injusto.

De lo dicho se desprende que en razón del carácter no necesario, contingente, susceptible de valoración, que revisten tanto las normas como los hechos, no puede darse aqui sólo un silogismo formal, que opera correctamente sobre realidades necesarias, no aptas para juicios de valor. Dice a este respecto Helmut Coing que "la aplicación de la ley no puede proceder nunca de un modo exclusivo en la for. ma de la inferencia puramente lógica, subsumiendo una determinada actividad vital bajo los conceptos generales de la ley. La aplica. ción de la ley es más bien siempre valoración de los hechos según los juicios de valor contenidos en el derecho"24.

3) Concebir la aplicación del derecho únicamente como un silogismo, implicaría la inmovilización o detención del mismo en el instante de la sanción legislativa. Ello en razón de que por ser el silogismo una inferencia necesaria, debe inevitablemente ser siempre idéntico e invariable. Debería inferirse siempre exactamente lo mismo frente a casos similares, quedando eliminada a priori toda posi-

M. Reale, Filosofia del diritto. Torino, Giappichelli. 1956, 228.

${ }^{24} \mathrm{H}$. Coing, Fundamentos de filosofia del derecho. Ariel. Barcelona. 1961. 274. 
bilidad de progreso en la jurisprudencia. La experiencia nos demues tra que en la realidad ocurre exactamente todo lo contrario; Michel Villey ha llegado a escribir en este sentido que "no hay nada más admirable que la lógica de nuestros magistrados, que consiste en ligar a viejos artículos del Código Civil, soluciones que dicen exactamente lo contrario"25. La jurisprudencia puramente silogística significa algo asi como la detención del derecho en un momento elegido arbitrariamente como originario; la paralización del ciencia jurídica, en el altar del deductivismo necesario de la lógica formal. Lo expuesto hasta aquí no significa afirmar que el jurista y el juez no hagan uso de silogismos al razonar el derecho. Lo que ocurre es que estos raciocinios tienen carácter instrumental, subordinado y ordenado al fin práctico-jurídico. Además, no sólo a través de silogismos razona el juez, sino también con argumentos retóricos y con razonamientos extralógicos o judiciales estrictos ${ }^{26}$.

4) Por último -y creemos que esto es lo realmente fundamentalla forma racionalista de concebir la función del juez, no tiene en cuenta el carácter eminentemente práctico de la actividad judicial. Considera que el magistrado debe operar como el matemático o el biólogo, a quienes no interesan los resultados prácticos de sus razonamientos y demostraciones. Pero el juez cumple una labor especifica en la vida social y su modo de razonar debe ser coherente con esa función; no puede hacerlo como un científico, porque su posición dentro del cuerpo social y de los órdenes de la realidad, es distinta. Su función es práctica, porque es práctico su objeto; es práctica pues se dirige hacia aquellas realidades que el hombre hace para el logro de su propia perfección, hacia unos modos de ser operables por el hombre, contingentes, mudables, históricos y cargados de valor $^{27}$. Su tarea es imprimir un cierto orden en la convivencia humana, en vistas al logro del bien común social y no reproducir como un mimeógrafo los textos de las leyes sistematizadas en los códigos. La función propia del juez, aquélla para la que los hombres instituyeron la judicatura, es hacer justicia entre ellos; regular sus relaciones sociales de modo que de ellas resulte la paz y el mejor bien

${ }^{25}$ M. Villey, Seize essais de philosophie du droit. Dalloz. Paris. 1969, 269. ${ }^{26} \mathrm{Cfr}$. G. Kalinowski, Introducción a la lógica juridica. Eudeba. Buenos Aires. 1973. 148.

${ }^{2 \pi} \mathrm{Cfr}$. J. Ruiz Giménez, Introducción a la filosofía del derecho. EPESA. Madrid. 1960. 76 ss. y 250 ss. 
de cada uno de los miembros del cuerpo social. Su tarea no es demostrar la verdad de las normas, sino encarnarlas en la vida social concreta, haciendo de ellas un eficaz instrumento del bien común ${ }^{28}$.

$$
\text { IV. L A R E A C C C I O }
$$

Llegados a este punto, debemos entrar en la segunda parte de nuestra exposición. Por elementales razones de espacio, como asimismo para evitar la reiteración de un tema frecuentemente tratado, vamos a omitir el desarrollo de todas aquellas reacciones contra la jurisprudencia conceptual que pueden calificarse -genéricamente- de irracionalistas o voluntaristas: la Escuela Histórica, la Escuela del Derecho Libre, el Sociologismo Jurídico, la Jurisprudencia de Intereses, el Pragmatismo Jurídico Norteamericano o la Teoría Pura del Derecho29.

En esta parte nos limitaremos a exponer esquemáticamente el modo o estructura del raciocinio judicial en el pensamiento realista clásico, comenzando por esbozar brevemente su concepción del derecho, tal como lo hiciéramos al exponer el pensamiento moderno.

El punto de partida del pensamiento clásico consiste en ubicar a lo jurídico en el campo de la praxis, de lo práctico. Como ya lo anticipáramos, pertenece al orden práctico todo aquello que el hombre hace para su propio perfeccionamiento; es la misma obra humana, en cuanto ordenada a la plena realización de las virtualidades contenidas en la naturaleza del hombre.

No creo que nadie pueda negar sensatamente que el derecho es algo que el hombre hace para tornar posible su vida social; que es una obra de la inteligencia y de la voluntad puestas al servicio de la convivencia. El hombre, frente a la necesidad de vivir en sociedad, crea el derecho para poner orden, para armonizar sus relaciones in. terindividuales; para que el obrar social de todos se oriente -directa o indirectamente- hacia el bien común.

${ }^{28}$ Cfr. T. D. Casares, La justicia y el derecho. Abeledo-Perrot. Buenos Aires. 1974. 156 ss.

${ }^{29} \mathrm{La}$ exposición detallada de esas doctrinas puede verse en $\mathbf{L}$. Legaz Lacambra, Filosofia del derecho. Bosch. Barcelona. 1961. 94 ss; H. Hernández, op. cit. 89 ss; E. García Maynez, Introducción al estudio del derecho. Porrúa. México. 1973. 337 ss.; C. Mouchet y R. Zorraquín Becú, Introducción al derecho. Abeledo-Perrot. Buenos Aires. 1970. 258 ss. 
Visto desde esta perspectiva práctica, el derecho no puede consistir sino en el orden introducido en las relaciones sociales para orientarlas a la perfección societaria; radica -en última instancia- en el concreto obrar social del hombre rectificado al bien común a través del bien de otro. Todo el proceso de lo práctico, culmina en el obrar concreto y circunstanciado; todo el orden de la praxis se encamina a lograr ese último resultado, que es el objetivo y fin inmediato que da razón de ser a todas las realidades que conforman un determinado ámbito de lo operable.

En el campo del derecho, toda la realidad compleja de lo jurídico integrada por leyes, sentencias, facultades, saberes jurídicos, sólo alcanza sentido y justificación en el concreto obrar justo de los hombres en sociedad. Sólo si en los hechos y concretamente, los hombres dan a cada cual la cuota que le corresponde en los bienes sociales, se justifica y adquiere razón de ser el complejo de normas, facultades de los sujetos y decisiones de los tribunales. Para la concepción realista del derecho, que lo visualiza desde el punto de vista práctico, repetimos que el derecho es -propia y formalmente- obrar humano justo; obra humana social, rectificada hacia el bien común. No interesa aquí principalmente la perfección de las normas, sino la del obrar humano social que esas normas contribuyen a conformar ${ }^{30}$.

Si partimos de esta concepción del derecho, el objeto último sobre el que el razonamiento judicial recae, es un obrar humano, contingente, histórico, mudable y con intrínseco valor ético y nuestra investigación ha de dirigirse a dilucidar cuál ha de ser el procedimiento intelectual adecuado a esta particular materia.

En los últimos años una larga serie de pensadores de primera linea han pretendido dar una respuesta a esta pregunta, partiendo de la especial naturaleza del objeto o materia del razonamiento judicial. Los más destacados son Theodor Viehweg y Wilhem Hennis,

${ }^{8} \mathrm{La}$ exposición en extenso de la doctrina realista del derecho puede verse en G. Graneris, Contribución tomista a la filosofia del derecho. Buenos Aires. 1973; L. Lachance, Le droit et les droits de l'homme. Puf. Paris. 1959, y del mismo autor, El concepto del derecho. SF. Buenos Aires. 1953; E. Pueyrredón, El concepto del derecho, en Universitas. Buenos Aires, 14 1970); F. Olgiati, Il concetto di guiridicita in San Tomasso d'Aquino. Vita e pensiero. Milano. 1944, como asimismo en las obras citadas de Villey. 
quienes sostienen que el pensamiento jurídico se elabora sobre la base de la tópica aristotélica y no de la lógica formal de los "Analíticos"31; Chaim Perelman y ia escuela belga, que proponen el nodelo de la retórica para el raciocinio jurídico32; Michel Villey, que luego de un estudio pormenorizado del pensar jurídico clásico, propone un modelo que llama cuasi-dialéctico ${ }^{33}$; Luis Recaséns Siches, quien elabora una lógica "razonable", propia de lo jurídico, por oposición a la lógica "racional" de las ciencias exactas ${ }^{\mathbf{3 4}}$; Georges Kalinowski, quien reivindica tanto la lógica moderna como la clásica doctrina de la prudencia35 y varios más. Pero lo que nos interesa destacar es que, no obstante las diferencias parciales de puntos de vista, en todos ellos encontramos una serie de afirmaciones que podemos resumir en los siguientes puntos:

1) Aceptación de que el objeto del raciocinio jurídico es contingente, variable y múltiple, fundamentalmente en razón de la libertad humana.

2) Afirmación del carácter valioso de la realidad jurídica, que la hace susceptible de juicios de valor y no sólo de juicios de realidad.

3) Convicción de la imposibilidad de tratar una materia de estas características con el sólo instrumento de la lógica formal, usada al modo de los saberes teóricos.

4) Necesidad de recurrir a un modo distinto de pensar, adecuado a la natura!eza del objeto jurídico, que razone sobre la base de problemas prácticos, buscando soluciones probables, no necesarias como las de los saberes teóricos y teniendo presente el elemento valioso esencial a todo lo jurídico.

${ }^{31}$ T. Viehweg, op. cit.; W. Hennis, op. cit.

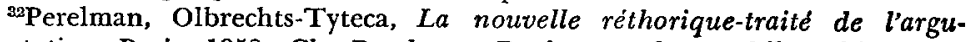
mentation. Paris. 1958; Ch. Perelman, Droit, morale et philosophie. IGDJ. Paris. 1976. Raisonement juridique et logique juridique, en APD 11. 1966.

М. Villey, Critique de la pensé juridique moderne. Dalloz. Paris. 1976; Le raisonement juridique dans l'histoire (Droit romain et moyen age), en Archiv Für Rechts und Sozialphilosophie, (Wiesbaden) 7 (1972); Quatre ouvrages récents sur la méthode du droit, en APD 16 (1971); Deux etudes recentes d'histoire du raisonement juridique, en APD 18 (1973), y las demás obras ya citadas.

${ }^{8}$ Recasens Siches, Experiencia juridica, naturaleza de la cosa y lógica razonable. FCE. México. 1971; Nueva filosofía cit.

${ }^{85} \mathrm{G}$. Kalinowski, De la specificité de la logique juridique, en APD 11 (1966) ; Introducción, it. 
Para la exposición de este modo propio de pensar lo práctico y en especial lo jurídico, la totalidad de los autores citados postulan un redescubrimiento o nueva explicación de la metodología clásica del pensamiento práctico, en especial de las exposiciones que efectuaran Aristóteles, Cicerón y Santo Tomás. Siguiendo ese mismo camino y a aquellos autores, vamos a exponer las notas propias del razonamiento práctico en el pensamiento realista, extrayendo las conclusiones que se refieran específicamente al razonamiento judicial.

V. LA C O N T I NGE N C I A D E L O J U R I D I C O

La primera de las notas del modo clásico del pensamiento jurídico, es concebirlo como un pensar acerca de un objeto contingente. $\mathrm{Pa}$ ra el realismo, el derecho es uno de esos objetos que -utilizando palabras de Aristóteies- "pueden ser de otra manera"36, es decir, que escapan a toda neces:dad y a todo determinismo; que pueden ser o no ser y en el caso de ser, ser de un modo u otro. El obrar social justo, objeto primero del saber jurídico, reúne todos los caracteres de lo humano: es esencialmente mudable, contingente, histórico; es producto de la actividad libre del hombre actuando en el tiempo y en el espacio. No hay aquí necesidad sino contingencia; no hay regularidad, sino multiplicidad circunstanciada. El derecho, como todo lo que sale de las manos del hombre, que construye en el tiempo irreparable y fugitivo, está sujeto a la caducidad, a la variabilidad y a la precariedad. El libre albedrío introduce un elemento de incertidumbre, que hace que ningún caso de derecho sea igual a otro y pueda ser tratado de modo idéntico. El obrar humano jurídico es irrepetible y único y por esta razón no puede ser pensado con elementos nocionales que fueron creados para razonar con objetos ciertos e inmutables, con cantidades o con densidades. Y si es acertado lo que dice a este respecto Aristóteles, que debe pretenderse dilucidar cada cosa "en la medida en que lo permite su materia; porque no se ha de buscar el rigor por igual en todos los razonamientos (...) sino sólo el que admite la naturaleza del asunto"37, es evidente que un razonamiento que tiene por objeto una realidad contingente, no puede pretender alcanzar una certeza abso-

${ }^{\mathbf{3 0}}$ Aristóteles, Etica, cit. v, $\mathbf{3}$.

${ }^{37}$ Idem r, 3. 
luta. En otros términos, en el ámbito de lo jurídico es imposible lograr la certeza, la seguridad en el juicio, que caracteriza a las ciencias exactas. Si bien podemos saber ciertamente que dos más dos suman cuatro, ningún juez puede tener la absoluta certidumbre de que la decisión adoptada era la única y absolutamente cierta. Por esto ha escrito Recaséns Siches que "sería un error entender la certeza y la seguridad en términos absolutos (...) lo más a que se puede llegar en derecho es a la formulación de juicios de probabilidad'38.

La mejor prueba de esto son la cantidad de fojas que debe llenar el juez para fundamentar, para dar el carácter de razonabilidad, a la decisión adoptada. Si la materia del razonamiento judicial fuera necesaria, las conclusiones del mismo aparecerían en forma evidente, tal como en el del matemático, que no debe dar razones que justifiquen el resultado de sus ecuaciones: si éstas han sido lógicamente bien llevadas la conclusión aparecerá espontáneamente.

El juez - por el contrario- enfrentado a una materia contingente y circunstanciada, se ve obligado a realizar un razonamiento problemático, cuyas conclusiones serán siempre discutibles. De lo contrario, y esto es evidente, no existiría la institución de los recursos, ni ocurririan cambios en la jurisprudencia.

La certidumbre de la verdad práctica y en especial de la verdad jurídica, es siempre relativa, relatividad que se acrecienta a medida que se desciende a la singularidad del caso concreto; en la norma general, que traza grandes directrices para la mayoría de los casos, surge con cierta evidencia su verdad o error, en razón de encontrarse todavía a cierta distancia de lo estrictamente práctico. Por el contrario, en la sentencia, en la decisión que se toma aquí y ahora en un caso singular, la inmersión en la contingencia es total y la certidumbre menor. "La razón práctica - escribe Santo Tomás- se ocupa de casos contingentes, que son el ámbito de las acciones humanas, y por eso aunque se dé necesidad en los principios más generales, cuanto más descendemos a lo particular, tanto más defectos encontramos"39. Lo más que puede pretender el juez, que opera con este orden del saber, es que su sentencia - si no "racional"- sea por Io menos "razonable", que existan razones objetivas que den fundamen-

-Recasens Siches, Nueva filosofia, cit. 295.

${ }^{20} \mathrm{~S}$. Tomás de Aquino, Suma teológica, 1-II, q. 94, a.4. 
to a su decision. Por esto ha escrito Roscoe Pound que la pretensión de obtener certidumbre "mediante la aplicación automática de reglas fijas a la conducta humana siempre ha sido ilusoria" 40 .

VI. L A P P A C C T I C I D A D

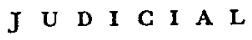

En segundo lugar, el razonamiento judicial se encuentra subordinado y ordenado siempre a un fin. Esto en razón de que su objeto es un sector del obrar libre del hombre que -en tanto que libre- está ordenado a ciertos y determinados fines. El libre albedrío implica la posibilidad de elección entre distintos fines y entre los múltiples medios que conducen a esos fines. Un obrar humano que careciese de fines no sólo es prácticamente imposible sino que teóricamente es un sinsentido 41 .

Por pertenecer el derecho al orden de la praxis que el hombre pone en sus actos para el logro de la perfección que le es propia, es un obrar teleológicamente ordenado; estructurado todo él en función de un fin, que en este caso resulta ser - como lo ha demostrado acabadamente Olgiati- el bien común de la sociedad política ${ }^{42}$. Y si el derecho es una realidad finalísticamente ordenada, el pensar jurídico es una forma de razonamiento que no tiene por objeto la contemplación de una verdad teórica, sino el dirigir la operación del hombre hacia sus fines propios. Como bien dice Leopoldo Eulogio Palacios, el saber práctico-jurídico es un saber normativo, que elabora directrices del obrar humano, ordenándolo a un fin; que determina lo que corresponde a cada uno en virtud de las exigencias de ese mismo fin ${ }^{43}$.

En virtud de lo expuesto, es claro que el razonamiento del juez no está encaminado a descubrir una verdad teórica, sino a solucionar un problema práctico; a decidir cuál es el obrar del hombre que se ajusta a las exigencias del fin del derecho en cada caso plantea-

${ }^{20} \mathrm{R}$. Pound, Introducción a la filosofia del derecho. Tea. Buenos Aires. 1972. 96.

${ }^{a}$ R. Jolivet, Tratado de Filosofia (Metafísica). Lohle. Buenos Aires. 1966, 284 ss.

${ }^{42} \mathrm{~F}$. Olgiati, Il concetto di giuridicitá, cit. 144.

${ }^{4}$ L. E. Palacios, Filosofia del saber, cit. 329. 
do. Desde esta perspectiva, la función del juez es ordenar la convivencia hacia el bien común, con el instrumento de la ley, en cada caso singular y concreto; y este objetivo debe ser tenido en cuenta en todas las etapas del razonamiento judicial. En efecto, al plantear el problema a resolver, al interpretar la ley, al emitir el último juicio práctico que decide qué es lo suyo de cada cual, el juez debe tener presente el fin general del ordenamiento juridico y el fin propio de cada institución específica. Esto se pone de manifiesto especialmente en lo que se refiere a la interpretación de la ley, ya que una será la interpretación que de una norma dé el doctrinario del derecho, que la conceptualiza en forma totalmente lejana a su operación concreta, tal como visualiza un cuadro un crítico de arte, que no se ve en la inmediata necesidad de pintarlo. Otra será, por el contrario, la interpretación del juez; ella ha de ser como la del artista, que se ve necesitado de aplicar las reglas de su arte al fin inmediato de lograr una obra bella; será la del juez una interpretación totalmente práctica, orientada a la mejor solución del caso que tiene entre manos; al logro del fin propio de la institución de que se trate, en una situación concreta y determinada ${ }^{44}$. Necesariamente su interpretación resultará distinta de la del doctrinario, que contempla a la ley desde una perspectica relativamente teórica; el juez debe ver en la ley un instrumento ordenado a un fin inmediato, la solución justa del caso $y$ a ese fin deben ordenarse todos los procedimientos intelectuales que siga en la hermenéutica de la norma. La pregunta del juez no debe ser cuál es la interpretación que está más de acuerdo con los principios de la ciencia del derecho, sino cuál de ellas es la que sirve al fin de la solución justa del caso en exa$m^{45}$. Lo contrario sería confundir su función con la de un catedrático o la de un publicista.

"Ambas interpretaciones, la del doctrinario y la del juez, son saberes prácticos, pero de distinto linaje: el del doctrinario es el que se llama, relativamente especulativo y relativamente práctico, pues el fin inmediato del conocer no es dirigir la acción concreta; el del juez es un saber completamente práctico, pues se constituye con el objeto inmediato de dirigir el obrar en un aqui y ahora circunstanciado. Cfr. S. Tomás de Aquino, Suma Teológica 1, q. 14, a.16; y también L. E. Palacios, Filosołia cit. 164 ss.

${ }^{45} \mathrm{Cfr}$. M. Villey, Leçons d'histoire de la philosophie du droit. Dalloz. Paris. 1962, 117 ss. 
VII. C A R A $\mathrm{C}$ T $\mathrm{T}$ R $\mathrm{R}$ V A $\mathrm{L}$ I O

En tercer lugar, el razonamiento judicial es un razonamiento ético o valorativo. Esto es consecuencia de lo afirmado en el punto anterior; en efecto, si el saber jurídico tiene por finalidad ordenar las relaciones y el obrar humano hacia el bien común, es evidente que ese saber reviste un esencial carácter de eticidad, eticidad que deriva del fin de bien común al que se encuentra subalternado; bien común que, por tratarse de la perfección del hombre en cuanto tal, reviste el carácter de un bien ético ${ }^{46}$.

Esto implica que el juicio judicial es un juicio de valor, se trata de un juicio acerca de un bien propio del hombre en un caso concreto. Una sentencia no es una afirmación axiológicamente indiferente, como puede serlo la de que los perros ladran; por el contrario, en ella hay un juicio acerca de la conveniencia de un cierto obrar para el bien de los hombres. El juez dice que una realidad es justa, es decir, ajustada a los títulos de otro, títulos que siempre, directa o indirectamente, tienen su fundamento en la perfección societaria ${ }^{4}$.

La consecuencia fundamental de esto para el modo propio del razonamiento judicial es de una gravedad no siempre percibida. No se advierte que, por esa razón, el saber del magistrado no es un saber de espectador, sino un saber de protagonista. La conciencia ética del juez se halla comprometida en el juicio que éste emite; el juez mismo es responsable de los resultados de su sentencia. Responsabilidad que no puede eludir transfiriéndola al lejano legislador; su función se desarrolla dentro del campo de las realidades éticas, de aquéllas que se refieren al bien del hombre en cuanto hombre, en este caso en su dimensión social. Por lo tanto, cualquier norma directiva que se establezca en este ámbito, por singularizada que sea, reviste un carácter esencialmente ético y compromete éticamente a quien la emite, con una responsabilidad personal que no puede ser transferida a una entidad abstracta como lo es la ley.

Esta eticidad o carácter valioso del razonamiento del juez, no implica una confusión de la moral personal con el derecho, ni tampo-

${ }^{46} \mathrm{Cfr}$. G. Soaje Ramos, Sobre la politicidad del derecho, en Boletín de Estudios Políticos. (Mendoza) 9195875 ss.

${ }^{47} \mathrm{Cfr}$. L. Lachance, El concepto cit. 296. 
co un olvido del elemento técnico que existe necesariamente en lo jurídico; tema este último con demasiadas virtualidades como para desarrollarlo en este lugar ${ }^{48}$. Lo que quiere significar es -lisa y llanamente- que el orden jurídico es parte del orden encaminado a la perfección del hombre y que, por lo tanto, en cualquier razonamiento que se realice en este campo, existe necesariamente una perspectiva ética o valiosa, que el juez debe considerar conjuntamente y por sobre los demás elementos del proceso.

Dicho en otros términos, que la consideración sobre la justicia debe formar parte del raciocinio del juez, no como algo sobreañadido, sino como algo intrínsecamente vinculado a su modo propio de razonar o juzgar. El magistrado no puede desvincularse de una consideración que pertenece a la esencia de su función. "El juez-dice Santo Tomás- es intérprete de la justicia" 49 , poniendo así de relieve la necesaria presencia de esa realidad valiosa en el razonamiento del magistrado.

\section{E L J U I C I O}

En cuarto lugar, para el pensamiento clásico, el razonamiento del juez no es deductivo, ni silogístico, ni axiomático, sino "prudencial"; ¿qué significa prudencia y cuál es su aplicación al campo de lo jurídico, que ha dado lugar al término jurisprudencia?

Santiago Ramírez ha escrito que prudencia es el "hábito operativo de la razón práctica inmediatamente ordenado a regular y dirigir todas las acciones humanas a su verdadero fin"50 y Pieper opina que “es la recta constitución de la razón práctica en tanto que ésta sabe lo que hay que obrar concretamente en el terreno de los medios [del obrar humano]"51. Dicho en otros términos, es la aptitud o disposición del intelecto práctico, que lo habilita para juzgar bien en el terreno de Io concretamente operable por el hombre, en el ámbito

${ }^{48}$ Sobre este tema puede verse J. M. Martínez Doral, La estructura del conocimiento juridico. Rialp. Pamplona. 1963. 67 ss. y J. Ferrer Arellano, Filosofía de las relaciones juridicas. U. de Navarra. Pamplona. 1963, 31 ss.

${ }^{40}$ S. Tomás de Aquino, Suma Teológica, II-II, q. 67, a.3.

${ }^{50}$ S. Ramírez, Introducción a la cuestión 47 de la Suma Teológica. Bac. Madrid. 1956, 13.

${ }^{51} \mathrm{~J}$. Pieper, El descubrimiento de la realidad. Rialp. Madrid. 1974, 79. Respecto a la problemática de la prudencia, véase el completísimo trabajo de P. Aubenque, La prudence chez Aristote. Puf. Paris. 1976. 
de to que debe hacerse aqui y ahora para el logro de un determinado fin. Es distinta de la ciencia, pues ésta versa sobre lo necesario y la prudencia acerca de lo contingente y es distinta de la técnica, porque esta última tiende a la perfección de una realidad exterior y la prudencia, a la perfección del hombre mismo, tanto en su dimensión individual como social52.

Si el derecho es -como ya lo hemos visto- el orden del obrar humano social hacia el bien común, la prudencia jurídica será la aptitud de discernir, en cada caso concreto, qué es derecho y juicio prudencial será el razonamiento que lleve acertadamente a esa singular determinación.

Los pensadores clásicos estudiaron detenidamente la estructura del razonamiento prudencial. Para ellos existían fundamentalmente tres elementos necesarios en ese modo práctico de pensar: la deliberación, el juicio y el mandato.

Por medio de la deliberación, que ha sido magníficamente estudiada por Carlos Sacheri en su trabajo "Aspectos lógicos del discurso deliberativo"53, el juez toma conocimiento de las realidades que debe ponderar, las analiza, las evalúa, indaga cuál es la verdad del caso y estudia sus posibles soluciones, en la búsqueda de aquélla que, en el caso concreto, sea la más conforme al fin de la institución y del derecho.

Etimológicamente deliberación se vincula con el término latino "consilium" o "considium", que significa la reunión de quienes se sientan juntos a dialogar acerca de una cuestión, a investigarla desde distintos puntos de vista. El trabajo intelectual del juez se realiza -efectivamente- de esta forma; él analiza y valora dialécticamente cada uno de los elementos que se presentan a su consideración: las normas, los hechos, las pruebas, los precedentes, los alegatos de las partes, las consecuencias prácticas de una $\mathbf{u}$ otra decisión. Estudia el caso tratando de captar todos sus aspectos, de sopesar o evaluar los distintos bienes en juego, de considerar adecuadamente las distintas posibilidades de solución del problema sujeto a su imperio. Tal como lo indica la etimología de la palabra, esta tarea se lleva a cabo

${ }^{52} \mathrm{Cfr}$. Aristóteles, Etica cit. vi, 5; acerca del tema de las relaciones de la prudencia con la técnica, vid. E. Pueyrredón, La autonomía de los técnicos, en Universitas, cit. 38 (1975) 82 ss.

${ }^{67}$ Cfr. H. Kelsen, Teoria pura del derecho. Eudeba. Buenos Aires. (1973) 175 ss. 
mejor entre varios que por uno solo, razón por la cual es que se procura que los más altos tribunales sean siempre colegiados 54 .

Es evidente, creo, que esta labor de indagación y valoración no se lleva a cabo silogísticamente. Tal como lo expusiéramos más arriba, consiste en un análisis teleologico y valorativo de las realidades en estudio; se busca cuál de las decisiones posibles se ajusta más a las circunstancias del caso, cuál de ellas conducirá a una solución más justa; qué norma es la más adecuada para la resolución del problema planteado, cuál es la más razonable de las argumentaciones expuestas por las partes. Se trata de un modo de razonar en el que se introducen constantemente los fines prácticos, las apreciaciones de justicia, los conflictos de bienes o valores. Nada tiene que hacer aquí el razonamiento de tipo teórico, necesario y uniforme ${ }^{x 5}$.

Realizada la deliberación, indagados los medios para solucionar el problema planteado y todos los elementos del mismo, escuchados los argumentos de las partes en el proceso, el juez decide, emite un juicio práctico acerca de cuál es la solución concreta que en mayor medida contempla las razones de bien particular y de bien común en el caso singular. Este juicio, que se expresa en la parte dispositiva de la sentencia, así como la deliberación se expresa en los considerandos, tiene una característica particular y problemática, que ya apuntamos hace un momento: nunca tiene certeza absoluta. Siempre existe en ese juicio un elemento de indeterminación, de inseguridad, como de salto en el vacío. Ningún juez sensato puede tener la certe. za absoluta de que su resolución es perfecta; a lo más, será la mejor dentro de las posibles. También aquí se percibe claramente la diferencia entre el juicio jurídico y el juicio científico-teórico, que siempre concluye con exactitud, o con casi exactitud, conforme lo sostenido por algunas teorias físicas contemporáneas.

Pero el juzgador que ya ha elaborado su juicio práctico, determinando qué es derecho en un caso concreto, no se detiene allí; no sólo dice qué es derecho, sino que lo prescribe; no sólo especifica la solución del caso, sino que manda que sea concretada en los he-

${ }^{\star}$ Cfr. S. Tomás de Aquino, Suma cit. I-II, q. 14, a.3; all escribe: "Es de advertir que en lo particular y contingente se deben tener en cuenta, para conocer una cosa con certeza, muchas condiciones o circunstancias, difícilmente observables por uno solo y que pueden ser percibidas con más seguridad por varios".

${ }^{56} \mathrm{Cfr}$. Digesto 1. 3. 17. 
chos; no sólo establece qué es lo suyo de cada cual, sino que impera que le sea dado.

Se pone así de manifiesto el carácter eminentemente normativo que reviste el razonamiento judicial, ya que el acto de imperio en que éste culmina es - ni más ni menos- una regla de conducta singularizada, que manda la realización de un determinado obrar en ciertas circunstancias. $Y$ aquí es donde se descubre con mayor claridad la presencia del elemento voluntario en el razonamiento judicial. Contrariamente a lo que sucede en el razonamiento teórico, que es producto casi exclusivo de la razón, en el razonamiento práctico y en especial en el del juez, aparece un elemento de voluntad, del querer, que concurre a otorgar carácter imperativo al resultado del último juicio práctico. Realizado éste por el juez, su resultado es un imperativo, un precepto, un mandato, actos que no pueden serlo de la sola razón, cuya función propia es el conocimiento, sino también de la voluntad, que tiende a lo conocido por el intelecto. La razón determina lo justo, pero es la voluntad la que mueve al hombre a lograrlo en la realidad existencial ${ }^{6}$.

En este aspecto, la doctrina de la prudencia representa una perfecta síntesis superadora de las opuestas posiciones del conceptualismo y el voluntarismo. Entre la posición de los exégetas, para quienes la sentencia era el resultado de una deducción puramente racional y la de Kelsen, quien sostiene que la decisión del juez es un acto de pura voluntad inmotivada, siempre que lo sea dentro del marco de posibilidades establecido por la norma ${ }^{57}$, se encuentra la doctrina de la prudencia; para ésta, la decisión judicial es un acto formalmente de la razón, pero transido de voluntariedad; implica una determinación racional de lo que es justo, pero no sólo una determinación sino también una valoración y un mandato, actos que no pueden realizarse sin el concurso de la voluntad, que quiere aquello que la razón le presenta como recto ${ }^{58}$.

Pero para querer efectivamente aquello que la razón presenta como bueno en las relaciones sociales, la voluntad debe hallarse rectificada por otra disposición, la justicia, que la inclina a dar al otro

${ }^{56} \mathrm{Cfr}$. J. Ferrer Arellano, op. cit. 53.

${ }^{ }{ }^{7} \mathrm{Cfr}$. H. Kelsen, Teoria pura del derecho. Eudeba. Buenos Aires. 1968. 166 ss.

${ }^{58}$ Cfr. S. Tomás de Aquino, Suma. cit. I-II, q. 17, a.1. 
aquello que le pertenece. Por esto Santo Tomás escribe que "el juicio es acto de justicia en tanto ésta inclina a juzgar rectamente, y de prudencia en cuanto ésta pronuncia el juicio"59. "La justicia -escribe Alvaro D'Ors- es la virtud o hábito que consiste en dar a cada uno lo suyo; pero presupone el conocimiento de ese suyo que se debe dar a cada uno. Este conocimiento es objeto de la prudencia $(\ldots)$. La justicia y la prudencia se enlazan como virtudes capitales de la función juzgadora: por la primera se induce al juez a juzgar bien, y por la segunda se averigua qué debe juzgar en cada caso para juzgar bien"60. La prudencia sin justicia -agregamos nosotros- no sale de su estado puramente intelectual, no pasa a la decisión concreta; por el contrario, el justo sin prudencia, no acertará sobre el objeto de su recto querer, no sabrá ciertamente qué cosa es efectivamente justa. Esta determinación de lo justo, que es el cometido propio de la prudencia, es un presupuesto de la justicia, pues no puede ser justo quien no conoce cuál es la verdad práctica en sus relaciones con los demás. Como bien dice Pieper, justicia es "la capacidad de vivir la verdad con el prójimo"01; verdad que es descubierta por el juicio de la prudencia.

Parecería a primera vista que nos hemos desviado de nuestro objetivo principal, pues hemos comenzado a hablar de la justicia. Pero en realidad no es así, pues todo el trabajoso razonamiento que hemos intentado describir hasta ahora, sólo cobra su sentido en la medida en que se ordena a la realización del obrar justo, fin inmediato y culminación de todo el proceso jurídico. Por ello escribía Cicerón que "la sabiduría sin justicia de todo valor carece"62.

El juez ha de realizar prudentemente lo justo con el instrumento de la ley; de lo contrario, no merecerá llevar el nombre de "juez", de quien Aristóteles dijo que debía ser "como una justicia animada"63, asignándole la función que llamó "casi divina", de hacer reinar la justicia entre los hombres.

${ }^{8} \mathrm{~S}$. Tomás de Aquino, Suma, cit. Ir-Ir, q. 60 a.1.

'A. D'Ors, Una introducción al estudio del derecho. Rialp. Madrid. $1963,12$.

1.1. Pieper, Prudencia y templanza. Rialp. Madrid. 1969, 18.

aicerón, M. T., De officis, II, 9.

${ }^{\infty}$ Aristóteles, Etica cit. v. 4. 
